\title{
Comparative Study on Solid-State and Metastable Liquid-State Aging for SAC305/Cu Joints
}

\author{
Shuang $\mathrm{Li}^{1} \cdot$ Xiao-Wu Hu${ }^{1} \cdot$ Wei-Guo Zhang ${ }^{2} \cdot$ Yu-Long $\mathrm{Li}^{1} \cdot$ Xiong-Xin Jiang ${ }^{1}$ \\ Received: 27 April 2018/Revised: 6 June 2018/Published online: 31 July 2018 \\ (C) The Chinese Society for Metals and Springer-Verlag GmbH Germany, part of Springer Nature 2018
}

\begin{abstract}
In order to study the influence of the physical state of solder on the interfacial reaction of dip-soldered $\mathrm{Sn}-3.0 \mathrm{Ag}-0.5 \mathrm{Cu} / \mathrm{Cu}$ system, two kinds of experiments were designed, including: (1) solid-state aging between the solder and $\mathrm{Cu}$ substrate; (2) liquid-state aging between the metastable supercooled liquid-state solder and $\mathrm{Cu}$ substrate. The aging times were 30,60 , 120 and $180 \mathrm{~min}$, respectively, and the aging temperature was $8{ }^{\circ} \mathrm{C}$ lower than the melting point of the $\mathrm{Sn}-3.0 \mathrm{Ag}-0.5 \mathrm{Cu}$ (SAC305) alloy $\left(217^{\circ} \mathrm{C}\right)$. The experimental data revealed that the physical state of the solder obviously affected the formation of the intermetallic compound (IMC), and resulted in the difference in the diffusion of atoms on the interface between the SAC305 solder and $\mathrm{Cu}$ substrate. The IMC interface after aging for 30 min presents unique characteristics compared with that of the sample after dip soldering. The IMC interface of solid-state aged SAC $305 / \mathrm{Cu}$ couple is relatively planar, while the IMC interface under metastable supercooled liquid-state aging conditions presents scallop-like shape.
\end{abstract}

Keywords Lead-free solder $\cdot$ Supercooling $\cdot$ Metastable liquid state $\cdot$ Aging $\cdot$ Intermetallic compound

\section{Introduction}

With the continuous development of miniaturization of multi-functional electronic products, chips are getting smaller and more powerful. Serving conditions of electronic elements become more and more complicated. Therefore, under the current developing trend of electronic products, it is necessary and important to study the effects of thermal cycling and thermal aging on the formation, growth and mechanical properties of the micro-connected interface $[1,2]$. Due to the destructive influence of $\mathrm{Pb}$ containing solder on the environment, the application of lead-free solder alloy received a wide attention [3]. Sn$3.0 \mathrm{Cu}-0.5 \mathrm{Ag}$ (SAC305) solder possesses good performance in thermal fatigue and solderability, and it has been

Available online at http://link.springer.com/journal/40195

Xiao-Wu Hu

huxiaowu@ncu.edu.cn

1 Key Lab for Robot and Welding Automation of Jiangxi Province, Mechanical and Electrical Engineering School, Nanchang University, Nanchang 330031, China

2 College of Mechanical and Electronic Engineering, Northwest A\&F University, Yangling 712100, China widely used in microelectronics packaging [4-8]. SAC305 solder alloy has been widely considered as a representative lead-free solder. $\mathrm{Cu}$ is the most common metal substrate due to its low cost, availability and good solderability.

Currently, the researches on SAC305 solder mainly concentrate on microstructure, the growth kinetics of intermetallic compounds (IMCs) and the improvement of mechanical properties of joints [9-12]. Shen et al. [13] investigated the microstructure evolution and growth mechanism of the interfacial IMCs during the solid-state aging process. It was found that the grooves provided convenient channel for $\mathrm{Cu}$ atoms passing through the previous IMCs. The $\mathrm{Cu}$ atoms reacted with solder alloy to form IMC grains, and the total IMC thickness increased with increasing aging time. Li et al. [14] reported the microstructural evolution of the interfacial IMCs during solid-state aging process. They found that at the initial stage of solid-state aging, the $\mathrm{Cu}$ atoms in IMCs were primarily from the supersaturated solder alloys. When the $\mathrm{Cu}$ atoms came from supersaturated solder alloy were consumed, the $\mathrm{Cu}$ atoms for the further growth of IMCs were primarily from the $\mathrm{Cu}$ substrate. Subsequently, the gaps between scallops $\mathrm{Cu}_{6} \mathrm{Sn}_{5}$ IMCs were gradually blocked with the IMCs growing, resulting in a slower consumption rate of $\mathrm{Cu}$ substrate. $\mathrm{Zhu}$ et al. [15] studied 
the effect of liquid-state aging on interfacial morphology of $\mathrm{Sn}-\mathrm{Cu}$ solder joint. The results showed that the growth of IMC was controlled by diffusion mechanism during liquidstate aging process. And the diffusion coefficient was two orders of magnitude higher than that of solid-state aging. However, it is acknowledged that there is no comparison regarding the growth kinetics of the $\mathrm{Cu}_{6} \mathrm{Sn}_{5}$ phase between $\mathrm{Cu}$ substrate and metastable supercooled liquid solder or solid solder with the same temperature and composition. Thus, the main purpose of this study is to compare the differences in interfacial reaction between solid-state and metastable liquid-state SAC305 solders with $\mathrm{Cu}$ substrate at the same temperature.

For this purpose, we have performed specific differential scanning calorimeter (DSC) experiments of interfacial reactivity between metastable liquid SAC305 solder and $\mathrm{Cu}$ substrate as well as between solid SAC305 solder and $\mathrm{Cu}$ substrate rigorously at the same temperature of $209{ }^{\circ} \mathrm{C}$. Afterward, a theoretical analysis of the interfacial reaction and the morphology of the reaction products are made in both experimental environments.

\section{Experimental}

In order to reveal the effect of the physical state of SAC305 solder on the growth kinetics and morphologies of interfacial intermetallic phases between solder and $\mathrm{Cu}$ substrate, we set up two experimental contents: (1) solid-state aging of the solid SAC305 solder/Cu substrate system; (2) liquidstate aging of metastable supercooled liquid-state SAC305 solder/Cu substrate system.

$\mathrm{Cu}$ substrate was obtained from electrolytic copper sheet (purity of $99.99 \%$ ) with the dimension of $30 \mathrm{~mm} \times 30$ $\mathrm{mm} \times 0.5 \mathrm{~mm}$. It was successively cut, ground and finely polished with diamond paste and ultrasonically cleaned. Afterward, the $\mathrm{Cu}$ substrate was dipped into conventional liquid RMA flux for $1 \mathrm{~s}$, followed by immersion in molten SAC305 solder filler metal at $250{ }^{\circ} \mathrm{C}$ for $3 \mathrm{~s}$.

In order to control the physical state of the SAC305 solder and the accurate reaction temperature in the aging process, experiments (STA449F3) of differential scanning calorimetry (DSC) have been applied to execute these experiments. After the dip soldering process, we completely removed the solder on one side and then cut it into small pieces of approximately $3 \mathrm{~mm} \times 3 \mathrm{~mm}$. The sample is named "dip-soldered sheet" in the following experiments.

In the process of reflowing, the melting point, solidification temperature and undercooling of the solder need to be monitored. We put the dip-soldered sheet into alumina crucible and then put into the DSC equipment. The dipping conditions (temperature, time) were determined in order to obtain good wetting and received an intimate contact between the SAC305 solder and the pure $\mathrm{Cu}$ sheet.

Figure 1a shows the temperature profile of the simple reflow process for the dip-soldered sheet sample, including heating up to $280{ }^{\circ} \mathrm{C}$ and cooling down to room temperature at a cooling rate of $10{ }^{\circ} \mathrm{C} \mathrm{min}-1$. Afterward, an exothermic peak was observed at about $201{ }^{\circ} \mathrm{C}$ during the cooling of the "dip-soldered sheet," as shown in Fig. 1a. This peak was due to the release of the solidification latent heat during the solidification of the solder after a classical reflow process. Figure $1 \mathrm{a}_{1}$ presents the typical DSC curve observed during a reflow process of the "dip-soldered sheet," indicating that the solidification of the SAC305 solder occurs at about $201{ }^{\circ} \mathrm{C}$ and that the melting temperature of the solder is $217^{\circ} \mathrm{C}$. (The undercooling is about $18{ }^{\circ} \mathrm{C}$.)

Figure $1 \mathrm{~b}$ shows the temperature-time profile of SAC305/Cu-soldered samples under the conditions of liquid-state aging at $209{ }^{\circ} \mathrm{C}$ for $60 \mathrm{~min}$, when the samples were heated up to $209^{\circ} \mathrm{C}$ and annealed at this temperature for the aged time varying from 30 to $180 \mathrm{~min}$. (The corresponding DSC curve is shown in Fig. 1b . $_{1}$ ) Figure 1c presents the time-temperature profile of SAC305/Cu-soldered samples under the conditions of metastable supercooled liquid-state aging at $209{ }^{\circ} \mathrm{C}$ for $60 \mathrm{~min}$. For these experiments, in order to melt the SAC305, the "dip-soldered sheet" needs to be heated up to $250{ }^{\circ} \mathrm{C}$ and afterward to be cooled down to $209{ }^{\circ} \mathrm{C}$. In order to reduce the temperature fluctuations, $5{ }^{\circ} \mathrm{C} \mathrm{min}{ }^{-1}$ was set in heating process and $3{ }^{\circ} \mathrm{C} \mathrm{min}{ }^{-1}$ in cooling process. All details concerning the DSC curves observed during these experiments are given in Fig. $1 c_{1}$. After each experiment, the exothermic peak was clearly detected in the case of a simple reflow process. If the exothermic peak was observed during cooling from 250 to $209^{\circ} \mathrm{C}$, the experiment should be considered as invalid. It meant that SAC305 solder solidified during the isothermal aging at $209{ }^{\circ} \mathrm{C}$. After isothermally aged at $209{ }^{\circ} \mathrm{C}$ for the desired aging time, the sample temperature was cooled down to the room temperature. After that, the aged sample was cut into two pieces: one for observing the cross-sectional structure and another for the top view of the IMC morphologies under scanning electronic microscopy (SEM). The common metallographic practice was followed to reveal the crosssectional view. To observe the top view of intermetallic compounds, majority of the solder was ground away.

The images were processed with image processing software by adjusting the contrast and brightness of the image, and then, the IMC layer was clearly separated and the pixel data of each layer of IMC were acquired. Through the following equation to obtain the interface layer IMC thickness $\left(L_{\mathrm{IMC}}\right)$ : 

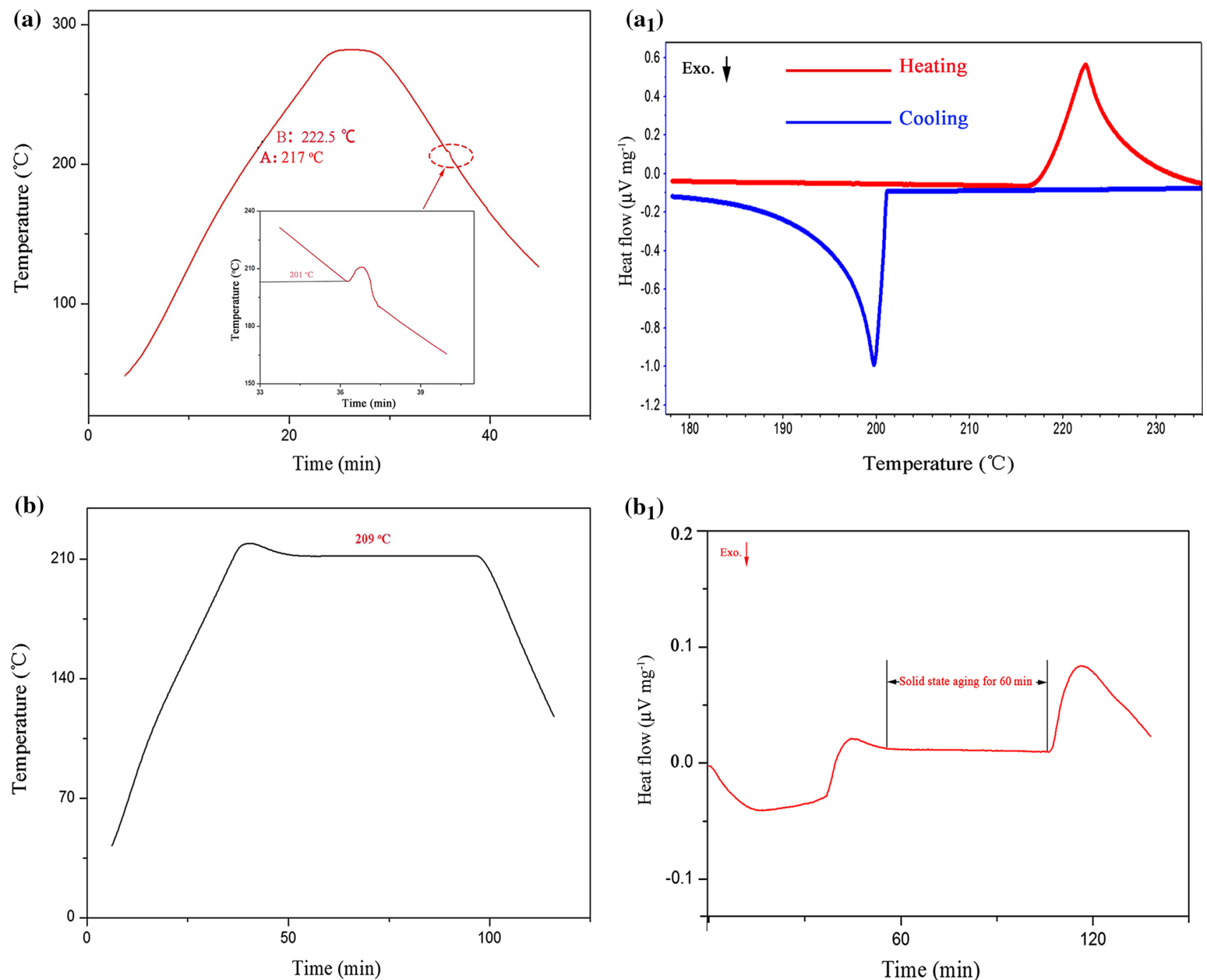

$\left(\mathbf{b}_{1}\right)$
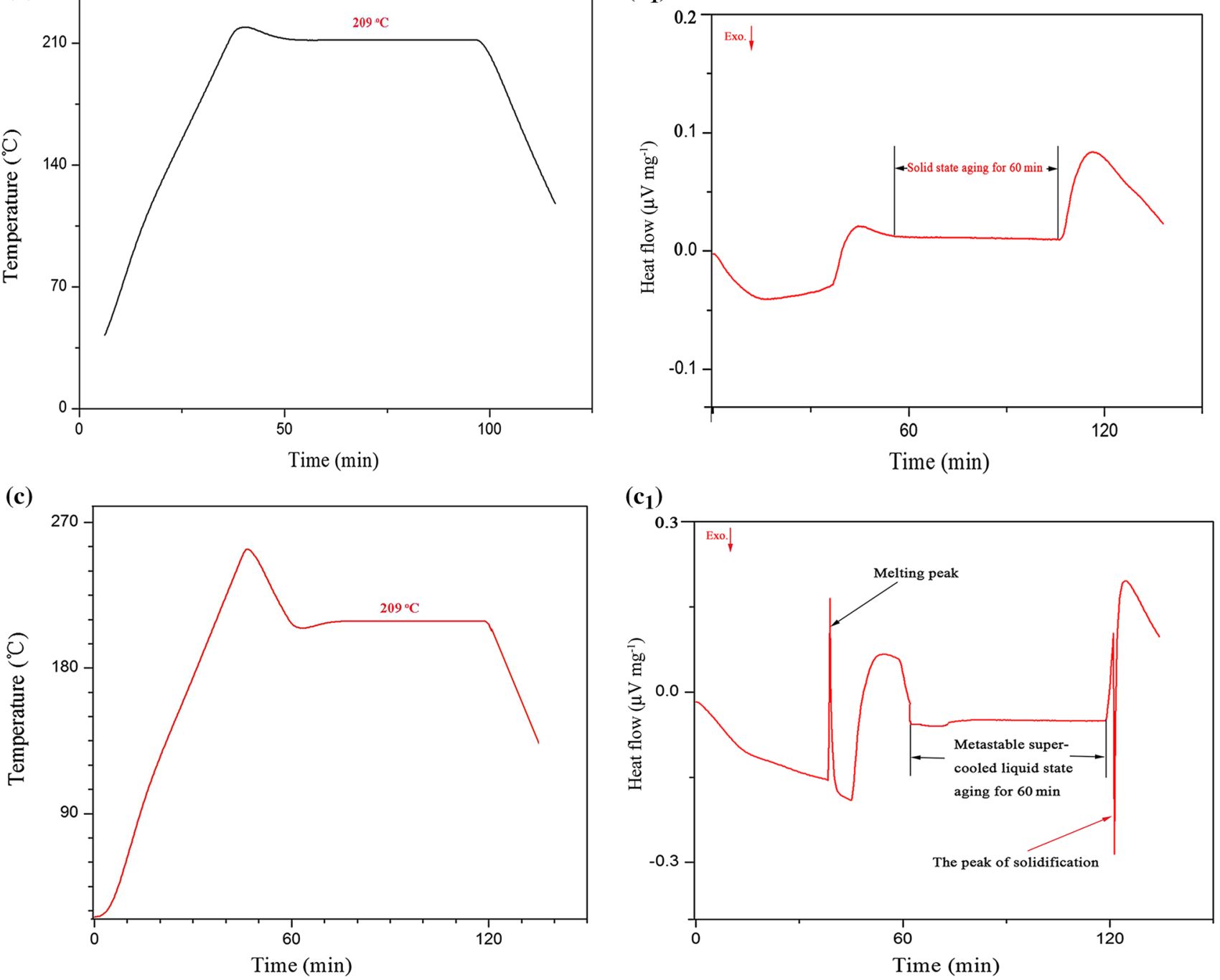

Fig. 1 Time-temperature curves a-c and exothermic curves $\mathbf{a}_{\mathbf{1}}-\mathbf{c}_{\mathbf{1}}$ of SAC305/Cu-soldered samples under conditions of reflowing $\mathbf{a}, \mathbf{\mathbf { a } _ { 1 }}$, solidstate aging at $209{ }^{\circ} \mathrm{C}$ for $60 \mathrm{~min} \mathbf{b}, \mathbf{b}_{\mathbf{1}}$ and metastable supercooled liquid-state aging at $209{ }^{\circ} \mathrm{C}$ for $60 \mathrm{~min} \mathbf{c}, \mathbf{c}_{\mathbf{1}}$ 
$L_{\mathrm{IMC}}=\left(N_{\mathrm{IMC}} / N_{\mathrm{SEM}}\right) \times L_{\mathrm{SEM}}$,

where $N_{\mathrm{IMC}}$ is the pixel of the IMC layer, $N_{\mathrm{SEM}}$ is the total pixel of the SEM image, and $L_{\mathrm{SEM}}$ is the actual height of the SEM image.

The grain diameter of the $\mathrm{Cu}_{6} \mathrm{Sn}_{5}$ at the interface of SAC305/Cu solder joints was measured by the top view of micrographs. In order to ensure the accuracy of the measurement and to reduce the measurement error, the measurement of each set of data was at least 20 grains and then found the average.

\section{Results and Discussion}

\subsection{Interfacial Microstructure Evolution}

Figure 2a shows the interfacial SEM micrograph of the SAC $305 / \mathrm{Cu}$ system after dip soldering at $250{ }^{\circ} \mathrm{C}$ for $3 \mathrm{~s}$. The place with higher brightness in the picture is the SAC305 solder alloy, the middle layer is the interfacial IMCs, and the black part is the $\mathrm{Cu}$ substrate. In the study of SAC305 solder by Zimprich et al. [16], the scallop-like interfacial $\mathrm{Cu}_{6} \mathrm{Sn}_{5}$ IMC and a small amount of $\mathrm{Cu}_{3} \mathrm{Sn}$ compound were formed at the interface of $\mathrm{SAC} 305 / \mathrm{Cu}$ substrate soldered at $265{ }^{\circ} \mathrm{C}$ for $500 \mathrm{~s}$. Those results indicate that the solid-state diffusion of interfacial elements is greatly dependent upon solder thickness during high temperature aging, that is, the thinner the solder layer is, the faster the $\mathrm{Cu}_{3} \mathrm{Sn}$ layer grows. However, no $\mathrm{Cu}_{3} \mathrm{Sn}$ was found at the interface of solder joints after dip soldering, which could be owing to the short dip soldering time in this experiment. Figure $2 \mathrm{~b}$ shows the cross-sectional microstructure of the solder joint aged under the solid state for $30 \mathrm{~min}$. The endothermic peak of the DSC curve was not observed from the temperature-time profile in Fig. $1 b_{1}$, thus ensuring that the sample was aged under solid-state conditions. Figure $2 \mathrm{c}$ shows the cross-sectional microstructure of the solder joint after aging for $30 \mathrm{~min}$ under the condition of metastable supercooled liquid state, and the energy-dispersive spectrometer (EDS) analysis results are shown in Fig. 2d, e. The experimental data showed that both $\mathrm{Cu}_{6} \mathrm{Sn}_{5}$ and $\mathrm{Cu}_{3} \mathrm{Sn}$ formed at the $\mathrm{SAC} 305 / \mathrm{Cu}$ interface. This phenomenon was similar to the previous research studied by Zimprich et al. [16]. An endothermic peak, corresponding to the reflow profile in Fig. $1 c_{1}$ in the DSC curve, can be observed during the heating process, thus ensuring the solder is completely melted. Subsequently, an exothermic peak can be observed during its cooling down to room temperature. After thermal aging, the microstructural evolution of reaction interface became much different, compared with that only after dip soldering. The interface after solid-state aging for $30 \mathrm{~min}$ presented relatively plane, while the interface under the conditions of metastable supercooled liquid-state aging for 30 min presented scallop-like shape. Furthermore, another obvious phenomenon occurred in the metastable supercooled liquid-state aging for $30 \mathrm{~min}$. $\mathrm{Cu}_{3} \mathrm{Sn}$ intermetallic layer formed at $\mathrm{Cu} / \mathrm{SAC} 305$ solder alloy interface, however, it did not form at the SAC305/Cu interface solid state aged for $30 \mathrm{~min}$, but $\mathrm{Cu}_{3} \mathrm{Sn}$ phase was observed after solidstate aging for $60 \mathrm{~min}$. The $\mathrm{Cu}_{6} \mathrm{Sn}_{5}$ compounds have a high
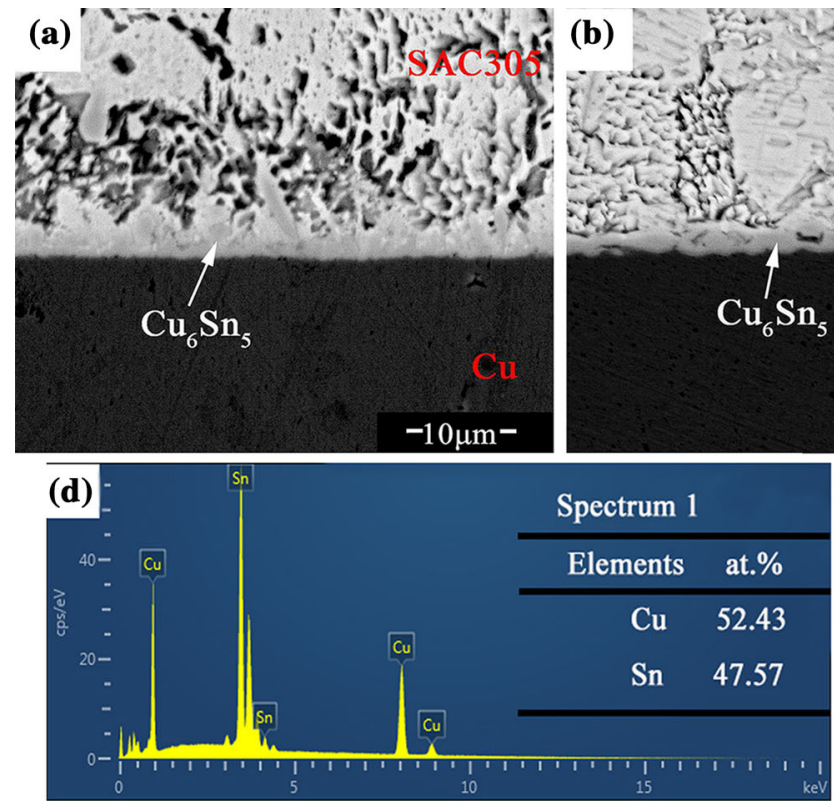

(b)
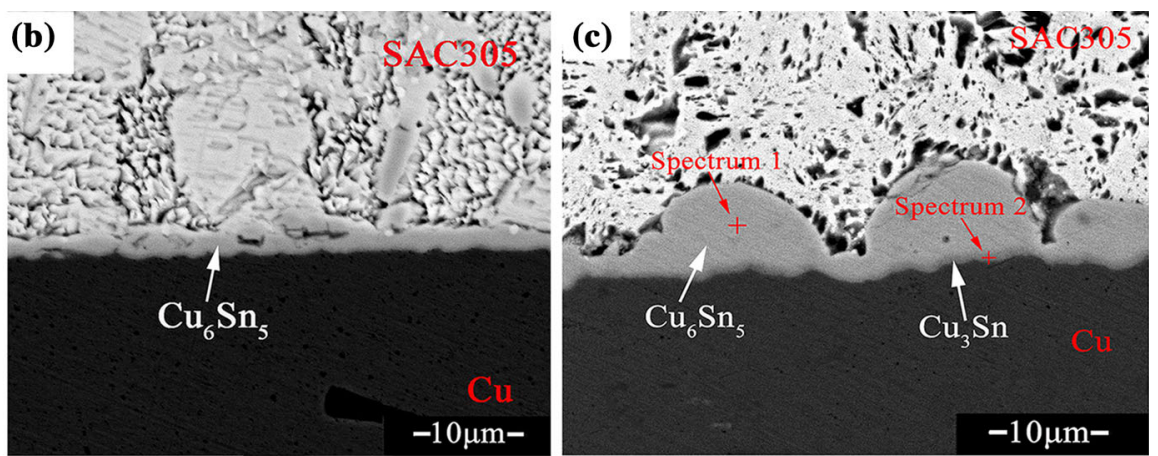

(e)

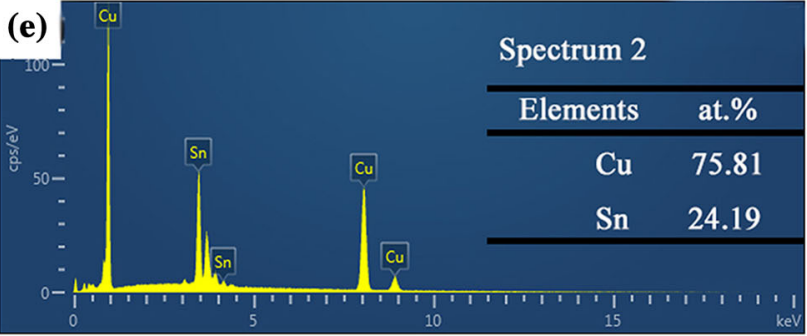

Fig. 2 Cross-sectional microstructures of $\mathrm{SAC} 305 / \mathrm{Cu}$ solder joints after dip soldering for $3 \mathrm{~s}$ a, solid state aged for $30 \mathrm{~min} \mathbf{b}$ and metastable supercooled liquid aged for $30 \mathrm{~min} \mathbf{c}$ and EDS analysis of spectrums $1 \mathbf{d}$ and 2 e from Fig. 1c 

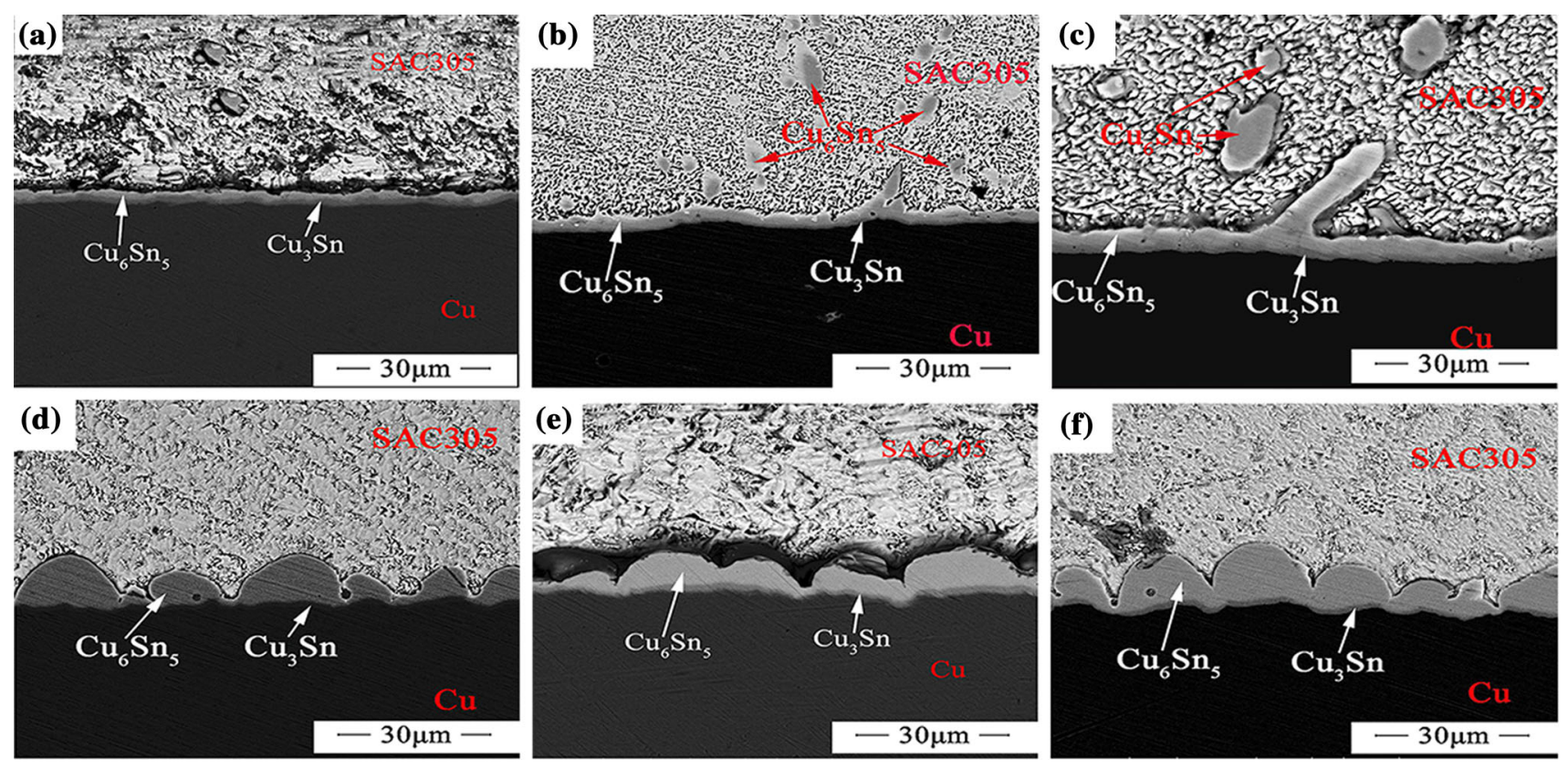

Fig. 3 Cross-sectional microstructures of SAC305/Cu solder joints under solid-state aging a-c and metastable supercooled liquid aging $\mathbf{d}-\mathbf{f}$ for $60 \min \mathbf{a}, \mathbf{d}, 120 \min \mathbf{b}, \mathbf{e}, 180 \min \mathbf{c}, \mathbf{f}$

rate of formation under the metastable supercooled liquid state, and when this compound accumulates to a certain degree, it will react with $\mathrm{Cu}$ atoms on the substrate to form $\mathrm{Cu}_{3} \mathrm{Sn}$.

Figure $3 \mathrm{a}-\mathrm{c}$ presents cross-sectional microstructures of SAC305/Cu solder joints aging under the solid state with aging time of 60,120 and $180 \mathrm{~min}$, respectively. Figure $3 \mathrm{~d}-\mathrm{f}$ presents cross-sectional views of the soldered sheets which were obtained by the reflow profile of Fig. 1c under the metastable supercooled liquid state, with aging time of 60,120 and $180 \mathrm{~min}$, respectively. It can be seen from the solid-state aged samples that a small amount of $\mathrm{Cu}_{6} \mathrm{Sn}_{5}$ phase is separated from the main interfacial IMC layer and embedded in the solder alloy. But this phenomenon cannot be observed during metastable supercooled liquid-state aging. The analysis results show that the interface wetting effect is better and the interface reaction rate between SAC305 solder and $\mathrm{Cu}$ substrate is faster during the liquid-state aging process. As a result, it is difficult for the $\mathrm{Cu}$ atoms on the substrate side to enter inside of the solder alloy through the initial IMC layer.

During the solid-state aging, the interface of the IMC layers presented relatively planar, while in the metastable supercooled liquid-state aging, the characteristic of the scalloped interface is obvious. During the liquidstate aging, the $\mathrm{Cu}$ atoms from substrate passed the nanochannels (Fig. 4) between the scalloped $\mathrm{Cu}_{6} \mathrm{Sn}_{5}$ phases and reacted with $\mathrm{Sn}$ atoms from solder, generating a new $\mathrm{Cu}_{6} \mathrm{Sn}_{5}$ phase and resulting in the rapid extension toward to the solder side [17]. The significant difference in

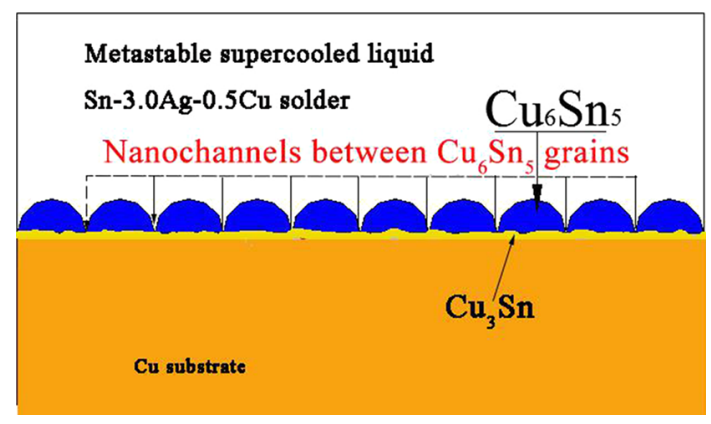

Fig. 4 Schematic diagram of nanochannels between $\mathrm{Cu}_{6} \mathrm{Sn}_{5}$ grains

the thickness of the interfacial IMC layers can be ascribed to two factors. One is that the $\mathrm{Cu}$ atoms could rapidly diffuse through liquid channels formed between some $\mathrm{Cu}_{6} \mathrm{Sn}_{5}$ scallops to react with $\mathrm{Sn}$ atoms. The existence of narrow channels between scallop-like $\mathrm{Cu}_{6} \mathrm{Sn}_{5}$ grains has been mentioned in previous literature [15]. Another one is that $\mathrm{Cu}$ atoms, diffusion in liquid solder is faster than that in the solid solder (according to Refs. [8, 18, 19]), resulting in that the thicknesses of the interface layers were significantly different for liquid-state aged joints.

Figure 5 depicts the X-ray diffraction (XRD) profile of the $\mathrm{SAC} 305 / \mathrm{Cu}$ solder joint interface. It was observed that four types of phases, including $\beta$-Sn, $\mathrm{Cu}_{6} \mathrm{Sn}_{5}, \mathrm{Ag}_{3} \mathrm{Sn}$ and $\mathrm{Cu}$ phases, were found. Figure 6 presents the morphologies of interfacial compounds grains in $\mathrm{SAC} 305 / \mathrm{Cu}$ solder joints under different physical states. Compared to that of solid-state aging, grains size under the aging condition of the metastable supercooled liquid state was greater. 


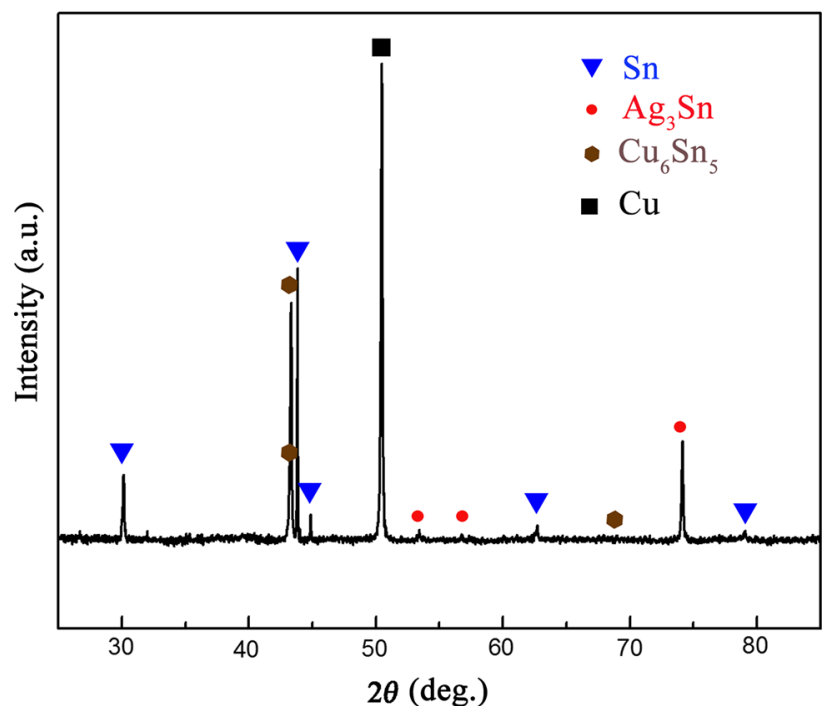

Fig. 5 XRD pattern of SAC305/Cu solder joint aged at $209^{\circ} \mathrm{C}$ for 60 min under supercooled metastable liquid-state condition

Furthermore, it can be seen from Fig. 6 that the $\mathrm{Ag}_{3} \mathrm{Sn}$ grains are embedded in the $\mathrm{Cu}_{6} \mathrm{Sn}_{5}$ grains boundary during the solid-state aging, while during the process of metastable liquid aging, $\mathrm{Ag}_{3} \mathrm{Sn}$ grains are attached on the surface of $\mathrm{Cu}_{6} \mathrm{Sn}_{5}$ grains, thus indicating that there are significant differences in grain growth mechanism between the two physical states. There are two main reasons to explain this microscopic morphology difference. On the one hand, the liquidity of $\mathrm{Ag}_{3} \mathrm{Sn}$ in liquid solder is better than that in solid solder. Under the aging condition of solid state, $\mathrm{Ag}_{3} \mathrm{Sn}$ is enriched in the edge of $\mathrm{Cu}_{6} \mathrm{Sn}_{5}$ grain boundary, which makes the grain boundary obtain more resistance for atom diffusion and the grain coalescence is slowed down. However, the interface of SAC305/Cu joint under the condition of metastable supercooled liquidstate aging, the enrichment of $\mathrm{Ag}_{3} \mathrm{Sn}$ at the grain boundaries of $\mathrm{Cu}_{6} \mathrm{Sn}_{5}$ is relatively low degree, which makes the grain boundary obtain lower resistance for atom diffusion, resulting in obvious differences in grain size between the solid-state aging and supercooled metastable liquid-state aging. On the other hand, it is difficult for the $\mathrm{Cu}$ atoms from the substrate passed through the initial IMC layers and reacted with $\mathrm{Sn}$ atoms from solder to formed new $\mathrm{Cu}_{6} \mathrm{Sn}_{5}$ compound during the solid-state aging. Due to the limited supply of $\mathrm{Cu}$ atoms for growth of $\mathrm{Cu}_{6} \mathrm{Sn}_{5} \mathrm{IMC}$, grain growth was impeded during the solid-state aging process. In contrast, due to the better interfacial solderability and the presence of nanochannels, the $\mathrm{Cu}$ atoms from the substrate passed through the IMC layers and reacted with the Sn atoms from the solder more intensely during the metastable supercooled liquid-state aging process, which resulted in the sufficient supply of $\mathrm{Cu}$ atoms for coarsening of $\mathrm{Cu}_{6} \mathrm{Sn}_{5}$ grains.
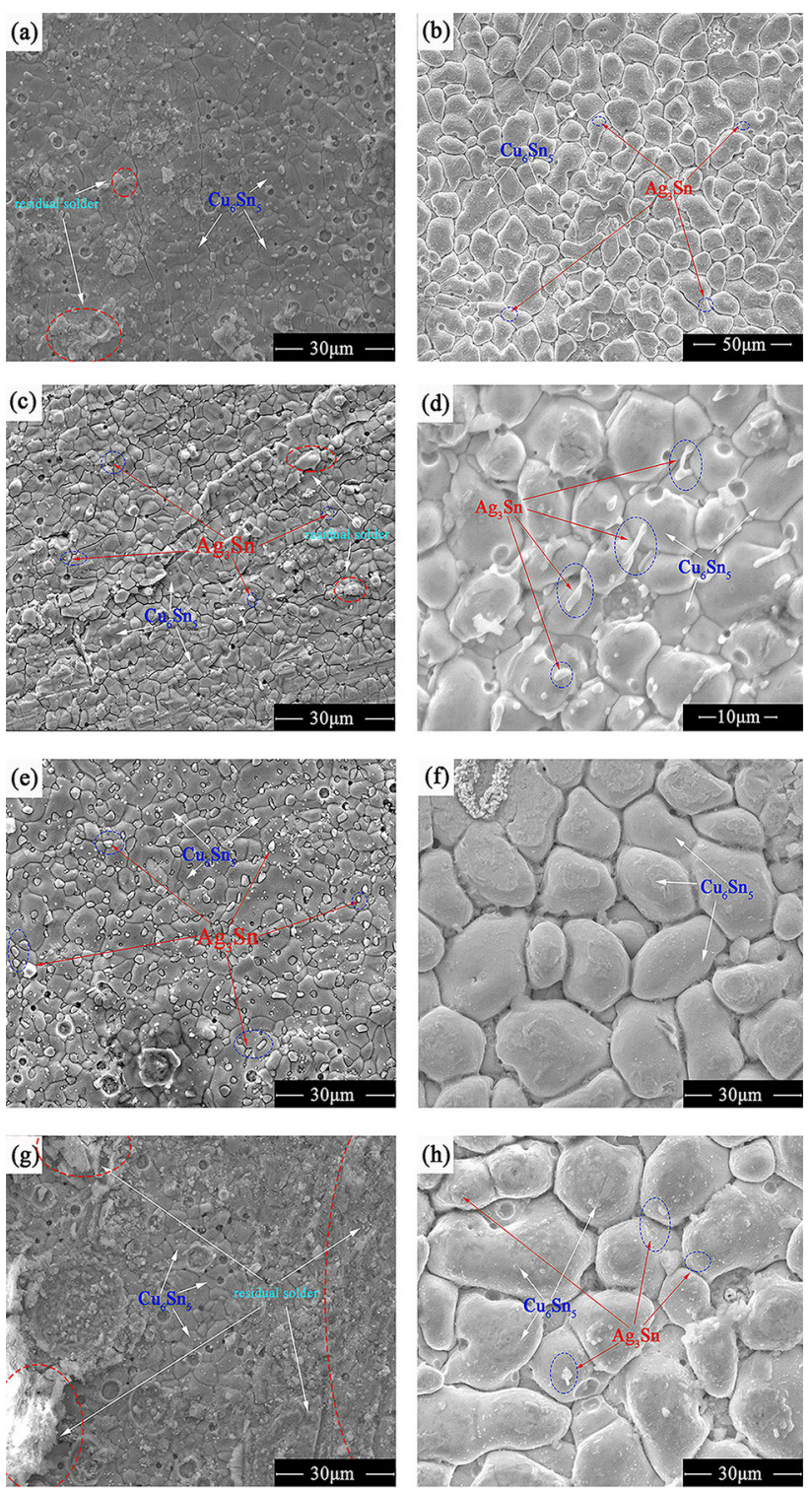

Fig. 6 Morphologies of $\mathrm{SAC} 305 / \mathrm{Cu}$ interfacial compound grains aged at $209{ }^{\circ} \mathrm{C}$ under conditions of solid-state aging a, c, e, $\mathbf{g}$ and metastable supercooled liquid aging $\mathbf{b}, \mathbf{d}, \mathbf{f}, \mathbf{h}$ for $30 \mathrm{~min} \mathbf{a}, \mathbf{b}, 60 \mathrm{~min}$ c, d, $120 \min \mathbf{e}, \mathbf{f}, 180 \min \mathbf{g}, \mathbf{h}$

The interfacial IMC layer thickness was obtained from their cross section of micrographs, and the results are listed in Table 1. The thicknesses of IMCs layers were 3.17, 3.84, 4.41 and $4.87 \mu \mathrm{m}$ for the SAC $305 / \mathrm{Cu}$ solder joints aged for $30,60,120$ and 180 min under the condition of solid state, respectively. However, when the samples were aged under the metastable supercooled liquid state for the same time, the thicknesses of IMCs layers were 6.25, 9.53, 11.27 and $12.23 \mu \mathrm{m}$, respectively. When the solder sheets were aged at different physical states, the thickness of IMCs layers increased with increasing aging time. But the physical state of the solder is one of the important factors affecting the 
Table 1 IMC thickness $(\mu \mathrm{m})$ with increasing aging time under various aging state

\begin{tabular}{lll}
\hline Aging time $(\mathrm{min})$ & Solid-state aging & Metastable supercooled liquid aging \\
\hline 30 & 3.17 & 6.25 \\
60 & 3.84 & 9.53 \\
120 & 4.41 & 11.27 \\
180 & 4.87 & 12.23 \\
\hline
\end{tabular}

thickness of the IMCs layers. Under metastable supercooled liquid-state aging, IMC layer is 2.5-4.8 times thicker than that in the case of solid-state aging. Despite the solder at the same temperature with different of physical state, due to the better interfacial solderability and the presence of nanochannels (as shown in Fig. 4), the $\mathrm{Cu}$ atoms from the substrate passed through the IMCs layer and reacted with the $\mathrm{Sn}$ atoms from the solder more intensely in metastable supercooled liquid state. In contrast, since the solid-state diffusion rate of the $\mathrm{Cu}$ atoms was relatively slow, it would limit the growth of the IMC layers during the solid-state aging. As a result, these abovementioned differences would result in that the thicknesses of the formed interfacial IMC layers were significantly different. Those results were similar to the conclusions proposed by Liashenko et al. [17].

The thickness of the IMC layer at the interface of the solder joint is related to the aging time. The relationship can be expressed by a power formula $[13,20]$ :

$X=X_{0}+A t^{n}$

where $X$ is the thickness of the IMC layers, $X_{0}$ is the initial thickness of the IMC layers, $A$ is the growth rate constant, and $n$ is the time index. Figure 7 shows the linear relationship between the total IMC thicknesses on SAC305/Cu interfaces and the square root of aging time. The error bars of the IMC equivalent thickness were obtained using the

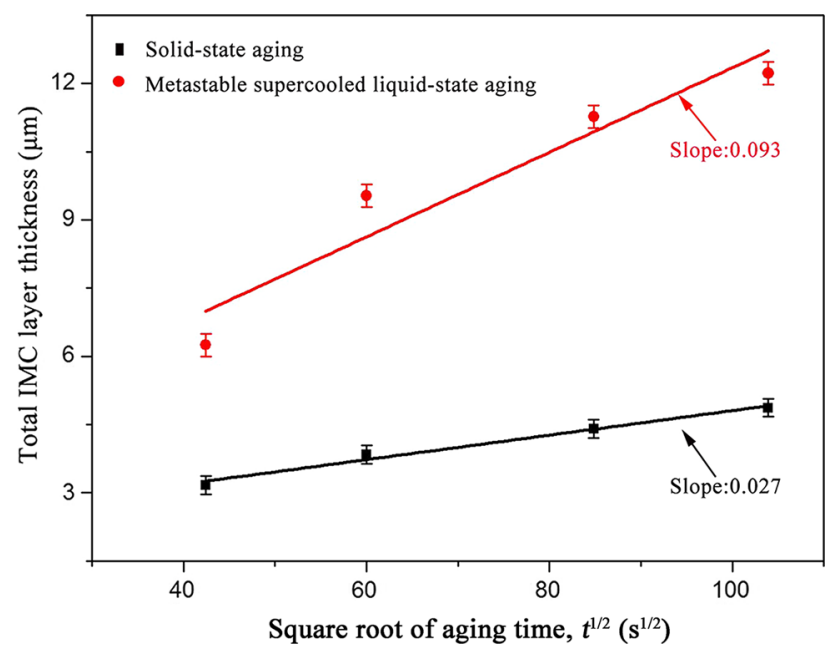

Fig. 7 Relationships of total IMC thickness on SAC305/Cu interfaces with square root of aging time on different aging conditions stand deviation function from the measured data. In this case, $n=0.5$, while the slope of the fitted straightening about solid state and the metastable supercooled liquid aging was 0.027 and 0.093 , respectively. The growth rate constant of the solid-state aging treatment was $7.29 \times 10^{-16} \mathrm{~m}^{2} \mathrm{~s}^{-1}$, while in the process of metastable supercooled liquid aging the growth rate constant was $8.65 \times 10^{-15} \mathrm{~m}^{2} \mathrm{~s}^{-1}$. During this solid-state aging process, the interface IMC growth rate of SAC305/ $\mathrm{Cu}$ solder joints was close to that reported by $\mathrm{Li}$ et al. [21]. Table 2 shows the average grain diameter after aging in different physical states. When the dip solder sheets were solid state aged for 30,60, 120 and $180 \mathrm{~min}$, the average grain diameters were $3.87,4.84,5.25$ and $5.88 \mu \mathrm{m}$, respectively. However, when they were under the metastable supercooled liquid-state aging, these were $10.69,13.60,16.28$ and $21.08 \mu \mathrm{m}$, respectively. The comparison of the two sets of data is made and shows that the diameter of the grains increased with increasing aging time. Compared to that of solid-state aging, the grains sizes of interfacial IMCs under the metastable supercooled liquid-state aging were 3-4 times higher.

The growth behavior of IMC grain size is usually expressed as follows [22, 23]:

$d=C t^{k}$

where $d$ is the average diameter of the $\mathrm{Cu}_{6} \mathrm{Sn}_{5}$ grains, $C$ is a constant, $k$ is the time index, and $t$ is the aging time.

Take the logarithm of both sides of Eq. (2):

$\ln d=C_{1}+k \ln t$,

where $C_{1}$ is a constant. As can be seen from Fig. 8, when the soldered sheets are aged under the condition of metastable supercooled liquid state, the slope of the straight line is 0.3371 . In the solid-state aging, the slope of the straight line is 0.22149 , which deviates from the theory that the theoretical IMC grain size should be proportional to the cube root of time $(k=1 / 3)$. This may be attributed to the grain growth affected by interfacial reaction and atomic interdiffusion [24]. The growth rate of the grain is faster when aging under liquid condition, comparing to solidstate aging. In the previous study [22, 25, 26], researchers proposed a flux-driven ripening (FDR) theory to study the coarsening behavior of interfacial $\mathrm{Cu}_{6} \mathrm{Sn}_{5}$ grains under solid-state aging conditions. In addition, the value of 
Table 2 Average grain diameter $(\mu \mathrm{m})$ with increasing aging time under various aging state

\begin{tabular}{lll}
\hline Aging time (min) & Solid-state aging & Metastable supercooled liquid aging \\
\hline 30 & 3.87 & 10.69 \\
60 & 4.84 & 13.60 \\
120 & 5.25 & 16.28 \\
180 & 5.88 & 21.08 \\
\hline
\end{tabular}

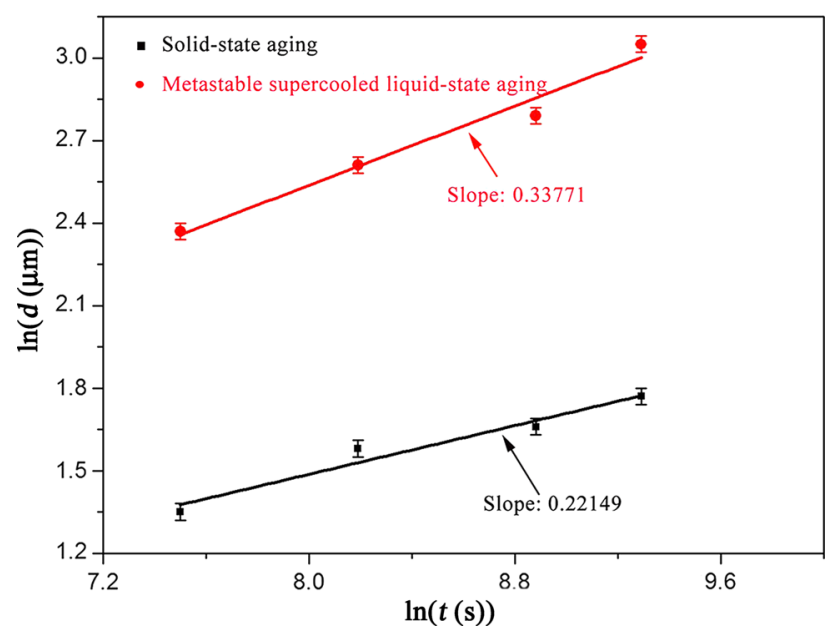

Fig. 8 Plots of $\mathrm{Cu}_{6} \mathrm{Sn}_{5}$ grain mean diameters $(d)$ versus aging time $(t)$ on logarithm coordinates at different physical state

$k$ exponent was calculated to be 0.28 , which is close to $1 / 3$, whereas, under the assumption given by the FDR model, $\mathrm{Cu}_{6} \mathrm{Sn}_{5}$ grains were hemispherical, coarsened by merging near grains. It can be ascribed to the Gibbs-Thomson effect, which results in that the $\mathrm{Cu}$ concentration near the surface of smaller grains is higher and $\mathrm{Cu}$ atoms in smaller grains are apt to merge into the molten solder and spread into larger one. And during the liquid-state aging, the $\mathrm{Cu}$ influences the coarsening of interfacial $\mathrm{Cu}_{6} \mathrm{Sn}_{5}$ grains.

Contrastively, during the solid-state aging, the change of hemispherical grains occurs. Moreover, the various diffusion pathways for $\mathrm{Cu}$ atoms are presented in the case of solid-state aging. As a result, it should be considered that the coarsening mechanism for interfacial IMCs under solid-state aging is different from that under liquid-state aging, when aged under solid-state conditions, the $k$ value is 0.22149 , a significant departure from $1 / 3$.

\section{Conclusions}

(1) It can be seen from the solid-state aged samples that a small amount of $\mathrm{Cu}_{6} \mathrm{Sn}_{5}$ phase is separated from the main interfacial IMC layer and embedded in the solder alloy. But this phenomenon cannot be observed during metastable supercooled liquid-state aging. The analysis results show that the interface wetting effect is better and the interface reaction rate between SAC305 solder and $\mathrm{Cu}$ substrate is faster during the liquid-state aging process. As a result, it is difficult for the $\mathrm{Cu}$ atoms on the substrate side to enter the inside of the solder alloy through the initial IMC layer.

(2) The liquidity of $\mathrm{Ag}_{3} \mathrm{Sn}$ in liquid solder is better than that of solid solder. Under the aging condition of solid state, $\mathrm{Ag}_{3} \mathrm{Sn}$ is aggregated at the edge of $\mathrm{Cu}_{6} \mathrm{Sn}_{5}$ grain boundary, which makes the grain boundary obtain more resistance for atom diffusion and the grain growth rate is slower. However, under the condition of metastable supercooled liquid state, the amount of $\mathrm{Ag}_{3} \mathrm{Sn}$ at the grain boundaries of $\mathrm{Cu}_{6} \mathrm{Sn}_{5}$ relatively decreases, which weaken the resistance for atom diffusion, resulting in obvious differences in the grain size between the solid-state aging and supercooled metastable liquid-state aging. (3) The coarsening mechanisms of interfacial $\mathrm{Cu}_{6} \mathrm{Sn}_{5}$ grains in solid-state and liquid-state reactions are different. In the FDR model, the aging under liquidstate $\mathrm{Cu}_{6} \mathrm{Sn}_{5}$ grains is assumed to be hemispherical. During the solid-state aging process, the pattern of hemispherical grains changes and the diffusion paths of $\mathrm{Cu}$ atoms are different from those of liquid solder.

Acknowledgements This work was supported financially by the National Natural Science Foundation of China (Nos. 51465039, 51665038 and 51765040) and the Natural Science Foundation of Jiangxi Province (No. 20161BAB206122), the Nature Science Basic Research Plan in Shaanxi Province of China (No. 2016JM5085).

\section{References}

[1] C.Y. Lin, C.C. Jao, C. Lee, Y.W. Yen, J. Alloys Compd. 440, 333 (2007)

[2] L. Zhang, L.L. Gao, J. Alloys Compd. 635, 55 (2015)

[3] C.W. Huang, K.L. Lin, Mater. Trans. JIM 45, 588 (2004)

[4] X.W. Hu, T. Xu, K. Li, Y.L. Li, X.X. Jiang, J. Alloys Compd. 690, 720 (2017)

[5] O.M. Abdelhadi, L.L. Ladani, J. Alloys Compd. 537, 87 (2012)

[6] H.B. Qin, X.P. Zhang, X.B. Zhou, J.B. Zeng, Y.W. Mai, Mater. Sci. Eng. A 617, 14 (2014)

[7] W.Q. Peng, E. Monlevade, M.E. Marques, Microelectron. Reliab. 47, 2161 (2007)

[8] X.J. Wang, Y.L. Wang, F.J. Wang, N. Liu, J.X. Wang, Acta Metall. 27, 1159 (2014) 
[9] A.M. Gusak, K.N. Tu, Phys. Rev. B 66, 115403 (2002)

[10] X.X. Tu, D.Q. Yi, J. Wu, B. Wang, J Alloys Compd. 698, 317 (2017)

[11] Q.S. Zhu, Z.F. Zhang, J.K. Shang, Z.G. Wang, Mater. Sci. Eng. A 435-436, 588 (2006)

[12] D.Z. Li, C.Q. Liu, P.P. Conway, J. Electron. Mater. 35, 388 (2006)

[13] J. Shen, M.L. Zhao, P.P. He, Y.Y. Pu, J. Alloys Compd. 574, 451 (2013)

[14] H.L. Li, R. An, C.Q. Wang, Z. Jiang, J. Alloys Compd. 634, 94 (2015)

[15] X.O. Zhu, L. Zhao, S. Tian, Y. Zhou, Electron. Compon. Mater. 35, 67 (2016)

[16] P. Zimprich, A. Betzwar-Kotas, G. Khatibi, B. Weiss, H. Ipser, J. Electron. Mater. 19, 383 (2008)
[17] O.Y. Liashenko, F. Hodaj, Acta Mater. 99, 106 (2015)

[18] S.W. Chen, Y.W. Yen, J. Electron. Mater. 28, 1203 (1999)

[19] J.O. Suh, K.N. Tu, G.V. Lutsenko, A.M. Gusak, Acta Mater. 56, 1075 (2008)

[20] P.T. Vianco, J.A. Rejent, J. Electron. Mater. 33, 991 (2004)

[21] X.Y. Li, F.H. Li, F. Guo, Y.W. Yao, J. Electron. Mater. 40, 51 (2011)

[22] H.K. Kim, K.N. Tu, Phys. Rev. B 53, 593 (1996)

[23] Ming Yang, Mingyu Li, Jongmyung Kim, Intermetallics 31, 177 (2012)

[24] Y. Tang, G.Y. Li, Y.C. Pan, J. Alloys Compd. 554, 195 (2013)

[25] H.F. Zou, H.J. Yang, Z.F. Zhang, Mater. Chem. Phys. 131, 190 (2011)

[26] A.M. Gusak, K.N. Tu, Phys. Rev. B 66, 115403 (2002) 